
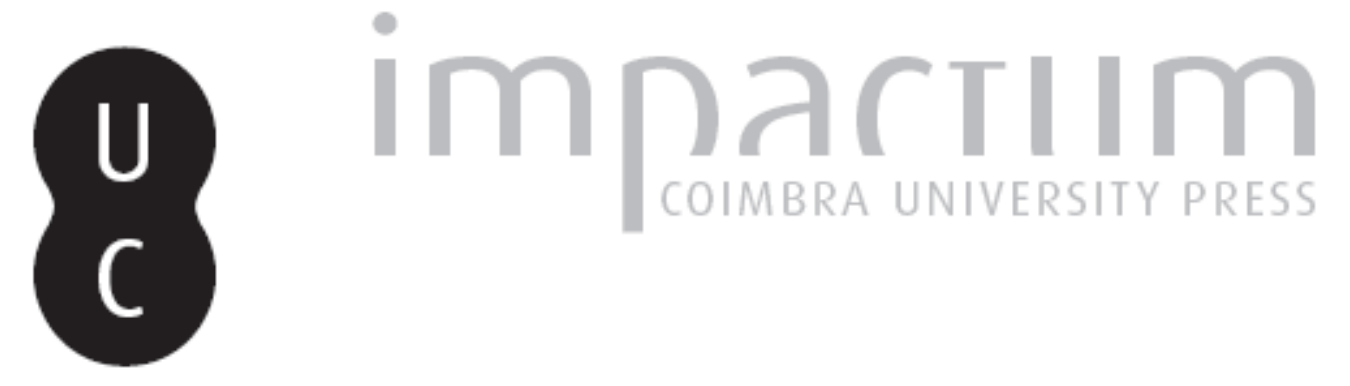

A Misericórdia de Coimbra: benfeitores e assistidos (1668-1910)

Autor(es): Mata, Cristóvão da

Publicado por: Centro de História da Sociedade e da Cultura

URL persistente:

URI:http://hdl.handle.net/10316.2/39433

DOI:

DOI:http://dx.doi.org/10.14195/1645-2259_12_12

Accessed : $\quad$ 26-Apr-2023 15:02:57

A navegação consulta e descarregamento dos títulos inseridos nas Bibliotecas Digitais UC Digitalis, UC Pombalina e UC Impactum, pressupõem a aceitação plena e sem reservas dos Termos e Condições de Uso destas Bibliotecas Digitais, disponíveis em https://digitalis.uc.pt/pt-pt/termos.

Conforme exposto nos referidos Termos e Condições de Uso, o descarregamento de títulos de acesso restrito requer uma licença válida de autorização devendo o utilizador aceder ao(s) documento(s) a partir de um endereço de IP da instituição detentora da supramencionada licença.

Ao utilizador é apenas permitido o descarregamento para uso pessoal, pelo que o emprego do(s) título(s) descarregado(s) para outro fim, designadamente comercial, carece de autorização do respetivo autor ou editor da obra.

Na medida em que todas as obras da UC Digitalis se encontram protegidas pelo Código do Direito de Autor e Direitos Conexos e demais legislação aplicável, toda a cópia, parcial ou total, deste documento, nos casos em que é legalmente admitida, deverá conter ou fazer-se acompanhar por este aviso.

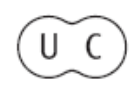


evista de História da Sociedade e da Cultura

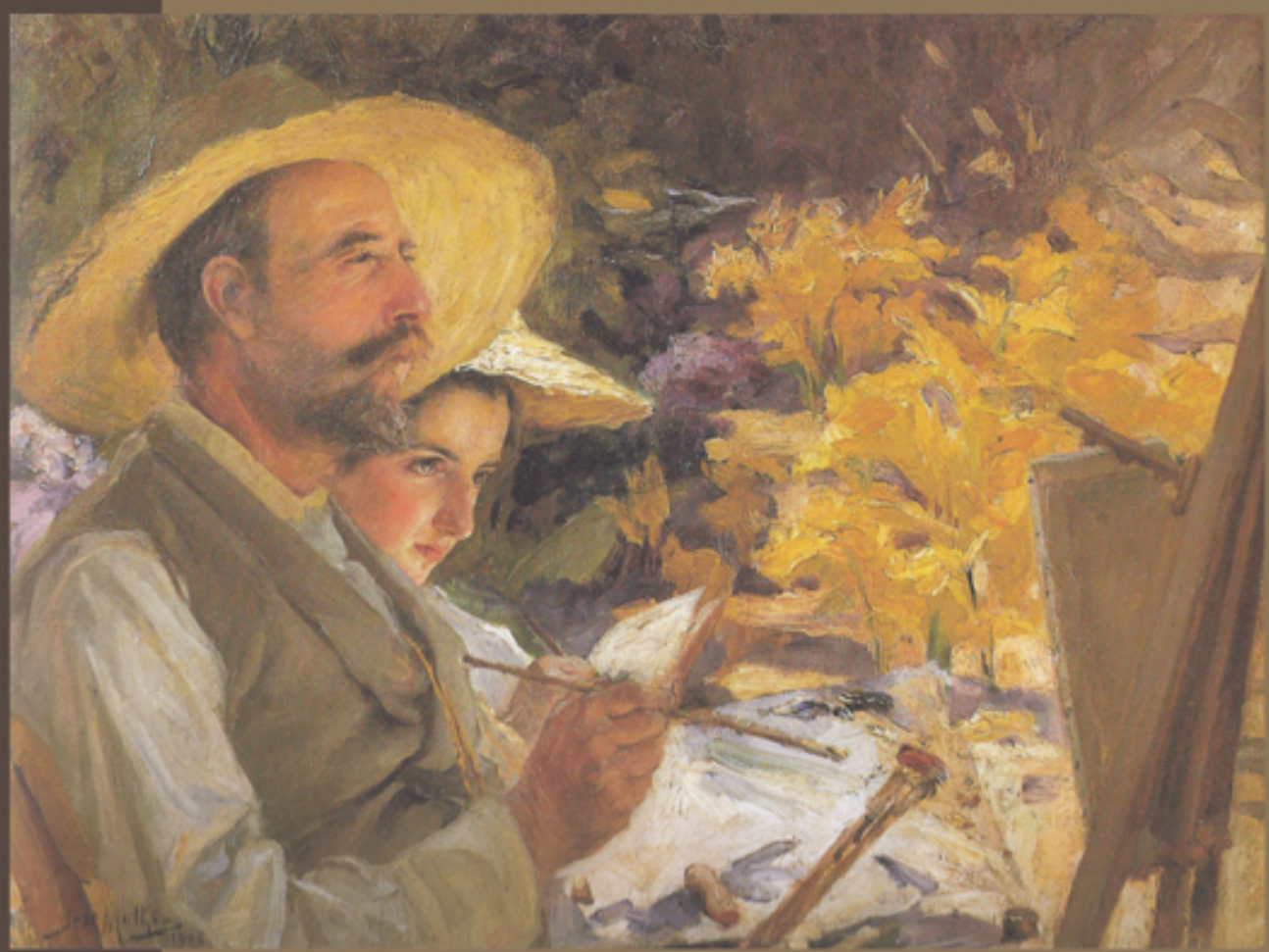

Centro de História da Sociedade e da Cultura Universidade de Coimbra 


\title{
A Misericórdia de Coimbra: benfeitores e assistidos (1668-1910)*
}

\author{
Cristóvão da Mata \\ Doutorando do $3^{\circ}$ Ciclo em Altos Estudos em História - Época Moderna \\ Universidade de Coimbra \\ cristovaomat@hotmail.com \\ Texto recebido em /Text submitted on: 25/01/2012 \\ Texto aprovado em / Text approved on: 01/03/2012
}

\section{Resumo/Abstract:}

Analisamos, no presente artigo, as doações recebidas pela Santa Casa da Misericórdia de Coimbra entre 1668 e 1910, tendo por objectivo apresentar os perfis sociais dos benfeitores e os grupos de beneficiados mais comuns e estabelecer uma relação entre as várias tipologias de benfeitores e as obras encomendadas, de modo a avaliar as diferenças decorrentes da transição do Antigo Regime para a Monarquia Constitucional.

In this paper, we'll analise the donations received by the Santa Casa da Misericórdia de Coimbra between 1668 and 1910, having as objective the exposition of the social profiles of the benefactors and the most prefered assisted groups, and establish a relation between the firsts and the ones whom they assists, in way to evaluate the diferences caused by the transition from the Old Regime to the Constitutional Monarchy.

Palavras chave/Keywords:

Beneficência; Misericórdia; Coimbra; Antigo Regime; Monarquia Constitucional.

Beneficence; Santa Casa da Misericórdia; Coimbra; Old Regime; Constitutional Monarchy.

* O presente texto resulta da pesquisa levada a cabo no âmbito de dois seminários de licenciatura e mestrado leccionados pela Professora Doutora Maria Antónia Lopes, a quem muito agradecemos pelo acompanhamento prestado e pelas indispensáveis críticas e sugestões, que representam uma dívida que, embora seja impossível de saldar aqui, não podíamos deixar de assumir. Eventuais erros e falhas serão, naturalmente, da nossa responsabilidade. 
"If one looks closely at what has happened to the world since the beginning of societies, it is easy to see that equality is prevalent only at the historical poles of civilisation. [...] Between these two extremes is found inequality of conditions, wealth, knowledge - the power of the few, the poverty, ignorance, and weakness of all the rest".

Alexis de Tocqueville ${ }^{1}$.

Esta afirmação tem muito que se lhe diga, nomeadamente quanto à assunção de que a igualdade entre homens foi e será possível apenas nos pólos extremos da História - a segura prevalência no início da civilização e a certeza da sua consumação futura. Não é, todavia, de menosprezar a observação de Tocqueville quanto à preservação desta desigualdade económica e social num vasto interlúdio civilizacional. Interessa-nos, pois, a desequilíbrio da balança social ali descrito por no caso aqui em estudo se verificar uma relação 'de cima para baixo', entre os «poucos» que detêm poder e os pobres, ignorantes e fracos, que assume a forma de proteç̧ão e controlo social desenvolvida mediante uma instituição, a Santa Casa da Misericórdia de Coimbra.

Atentar-se-á não apenas aos promotores da assistência mas também aos grupos assistidos, uma vez que ambos repartem o protagonismo desta trama. Limitar o campo de análise a estes últimos constituiria uma redução nas possibilidades reais de interpretação da acção assistencial analisada. Concentramo-nos tão-só nos primeiros resultaria igualmente nessa indesejada limitação, mas também em incorrer naquele vício de admirar os poderosos e negligenciar os desvalidos que Adam Smith destacou numa das suas famosas obras ${ }^{2}$.

O marco inicial do período aqui em estudo justifica-se por o ano de 1668 corresponder ao principiar de «uma conjuntura promissora, que se acentuou decisivamente no decurso do reinado de $\mathrm{D}$. João $\mathrm{V} \gg{ }^{3}$. Quanto à prossecução do estudo até ao ano da Implantação da República Portuguesa, motivou-nos a intenção de efectuar uma análise sobre um arco cronológico de longa

1 Memoirs on Pauperism. Londres: Civitas, 1997, p. 20.

2 The Theory of Moral Sentiments. Londres: Penguin, 2009, p. 87.

3 ARAÚJO, Maria Marta Lobo de e PAIVA, José Pedro - Portugaliae Monumenta Misericordiarum. Vol. VI: Estabilidade, grandeza e crise: da Restauração até ao final do reinado de D. João V. Lisboa: União das Misericórdias Portuguesas, 2002, p. 7. 
duração que nos permita estabelecer diferenças entre as doações efectuadas durante o Antigo Regime e as da Monarquia Constitucional.

Importa, por isso, tendo em conta as tranformações inerentes ao passar do tempo, pôr-se a claro uma série de termos e conceitos concernentes à base doutrinal motivadora das doações à Misericórdia. Isto pelo simples facto de os termos beneficência, o seu sinónimo benemerência, caridade e filantropia, não obstante remeterem para uma prática comum, a de ajudar o próximo, de atenuar o sofrimento alheio, conterem diferentes significações.

O primeiro vocábulo, quando empregue por autores religiosos, assumia-se como um «acto de bondade, de fazer bem, geralmente atribuído a Deus ou, também, como manifestação de caridade». Depois, no século XVIII, por influência das Luzes francesas, o seu significado secularizou-se, vindo seguidamente a ser acolhido pelo discurso liberal português ${ }^{4}$. Caridade demarca-se daquele conceito por ser «um sentimento e a beneficência um acto», devendo ser entendida como o amor a Deus manifestado e revelado através das obras dirigidas a Ele e ao Homem. Em virtude da sua ligação ao divino, ambos os conceitos inserem-se num quadro de valores afecto às sensibilidades religiosas. Num sentido completamente contrário ao da caridade, a filantropia abdicava de Deus, dirigia-se única e exclusivamente ao Homem e, consequentemente, não foi acolhida pela Igreja ${ }^{5}$. Posto isto, recorreremos tão-só aos termos beneficência (e benemerência) e caridade quando nos referimos ao Antigo Regime, mantendo-se ambos quando evocada a centúria de Oitocentos, embora em sintonia com o significado de filantropia ${ }^{6}$.

As misericórdias portuguesas foram, por certo, durante a Época Moderna, «instituições que visavam proteger indivíduos ou grupos considerados carentes e merecedores de protecção» ${ }^{7}$. De protecção mas não só. A par desta intenção caminhava, também, uma intenção de controlo social que

4 LOPES, Maria Antónia - Protecção Social em Portugal na Idade Moderna. Coimbra: Imprensa da Universidade, 2010, p. 27.

5 LOPES, Maria Antónia - Protecção Social..., cit., p. 26-28.

6 Cf. LOPES, Maria Antónia e PAIVA, José Pedro - Portugaliae Monumenta Misericordiarum. Vol. 8: Tradição e Modernidade: o período da monarquia constitucional (1834-1910). Lisboa: União das Misericórdias Portuguesas, 2010, p. 11.

7 LOPES, Maria Antónia - Protecção Social..., cit., p. 25. 
procurava regular «a actividade dos outros em função de valores próprios, visando eliminar os comportamentos desviantes individuais e colectivos» ${ }^{8}$.

Verificar-se-á adiante que determinados benfeitores não se limitavam a encomendar obras assistenciais, já que também estipulavam certos requisitos, de conduta moral ou de outra ordem, a serem preenchidos pelos candidatos ao legado. Tal prática, porém, foi coerente com as mentalidades de cada época e não assumiu um modelo rígido, inalterável e impermeável às mudanças provocadas pelo passar dos anos.

Muito embora nos dediquemos presentemente à protecção social praticada indirectamente - assim a designamos por estes benfeitores não assistirem o desvalimento por eles próprios mas mediante a Santa Casa cuja actividade financiavam - por homens e mulheres nos perídos do Antigo Regime e da Monarquia Constitucional, as raízes doutrinais desta prática de converter a riqueza privada em ajuda aos grupos sociais mais frágeis assentam em séculos anteriores.

Quando no século XIII a ordem franciscana aceitou a legitimidade do enriquecimento pessoal estipulou como contrapartida a colocação dos bens acumulados ao serviço dos pobres. Mediante este exercício altruísta estabelecia-se uma íntima relação entre Deus e o caridoso, o qual garantia a salvação da alma a troco da canalização dos seus bens materiais para a irradicação do sofrimento dos pobres ou em serviço das almas dos defuntos suspensas no Purgatório9.

Foi à luz desta ideia que em 1498 se erigiu a primeira Santa Casa portuguesa, a de Lisboa, cujo compromisso visava as catorze obras de misericórdia (sete espirituais: ensinar, aconselhar, castigar, consolar, perdoar, sofrer pacientemente e rezar pelos vivos e mortos; e sete corporais: resgatar os cativos, visitar os presos, curar os doentes, cobrir os nus, alimentar os famintos e dar de beber aos sequiosos, albergar peregrinos e enterrar os mortos). Cobria, assim, um vasto leque de serviços de assistência ${ }^{10}$.

8 LOPES, Maria Antónia - Protecção Social..., cit., p. 26.

9 SÁ, Isabel dos Guimarães - As Misericórdias Portuguesas de D. Manuel I a Pombal. Lisboa: Livros Horizonte, 2001, p. 22-23.

${ }^{10}$ SÁ, Isabel dos Guimarães e LOPES, Maria Antónia-História Breve das Misericórdias Portuguesas. Coimbra: Imprensa da Universidade, 2008, p. 24-26. 
Posteriomente, substituiria algumas das obras de misericórdia por novas práticas de assistência, especialmente de índole física ${ }^{11}$.

No primeiro século de existência das misericórdias, estas obras foram financiadas por diversas fontes - esmolas, doações régias, monopólio de determinados serviços, incorporação de outras instituições (hospitais, gafarias, confrarias locais) e respectivas fontes de rendimento. Na centúria seguinte, sofreu o património das Santas Casas um aumento significativo, fenómeno ao qual não foi alheio a encomendação de legados e a instituição de capelas ${ }^{12}$.

A popularização da ideia do Purgatório, com maior vigor a partir das sessões conciliares de Trento, despoletou a massiva encomendação de missas por almas de defuntos ${ }^{13}$. À medida que o prestígio das Misericórdias ia aumentando, muitos indivíduos entendiam ser justificável legar-lhes o seu património por via de testamento ${ }^{14}$. Assim, interpelados pelos clérigos sobre o destino a dar aos seus bens, os testadores não hesitavam, na iminência da sua morte, em cumprir os preceitos da filosofia indulgencial sobre o valor da esmola e da relação desta com a remissão dos pecados ${ }^{15}$.

Estes capitais, no entanto, não eram aplicados directamente pelas misericórdias nas obras de caridade. Malgrado a condenação dos empréstimos pelo direito canónico e pelas Ordenações, as misericórdias revelaram poucos escrúpulos em financiar a sua actividade com dividentos gerados por empréstimos ${ }^{16}$, o que garantia a subsistência de um fundo destinado ao exercício da beneficência. Da parte dos benfeitores assumiu-se uma posição semelhante. Muitos foram aqueles que, por testamento, doação simples ou contrato, entregaram à Santa Casa de Coimbra um pecúlio destinado a

${ }^{11}$ LOPES, Maria Antónia - Protecção Social..., cit., p. 57.

${ }^{12}$ LOPES, Maria Antónia - Protecção Social..., cit., p. 52-54.

${ }^{13}$ SÁ, Isabel dos Guimarães - As Misericórdias Portuguesas..., cit., p. 41 e ARAÚJO, Maria Marta Lobo de e PAIVA, José Pedro - Portugaliae Monumenta Misericordiarum. Vol. 6, cit., p. 13. Este fenómeno, por outro lado, podia não se revelar rentável para as misericórdias nem fácil de administrar. No decorrer dos anos, o que se verificou foi uma tendência de acumulação e de incapacidade de resposta por parte das Santas Casas - cf. LOPES, Maria Antónia - Proteç̧ão Social..., cit., p. 54.

${ }^{14}$ SÁ, Isabel dos Guimarães e LOPES, Maria Antónia - História Breve..., cit., p. 56.

${ }^{15}$ ARAÚJO, Ana Cristina - Morte edificante e vida inquieta: a disciplina dos afectos nas Ars Moriendi e nos testamentos. Revista Igreja e Missão. 1994, p. 111.

${ }^{16}$ SÁ, Isabel dos Guimarães - As Misericórdias Portuguesas..., cit., p. 49-50. 
financiar uma ou mais obras, estipulando que o capital doado fosse colocado a juros para com o respectivo rendimento se financiar o legado ${ }^{17}$.

Beneficência, como já se disse, possibilitada por um conjunto de homens e de mulheres cujas doações financiavam e suportavam, em parte, a actividade da Misericórdia de Coimbra. Entre 1668 e 1910, a tomarmos em consideração exclusivamente a simples relação entre doador(es) e legado(s), verifica-se a existência de cento e dez doações. No total, porém, o número efectivo dos benfeitores ascende a cento e vinte e três, pois as doações foram realizadas ora individualmente ora em parceria, entre esposa e esposo ou irmã e irmão (ou irmã).

Neste universo, existe uma certa homogeneidade em relação ao local de residência e/ou falecimento dos benfeitores. Vinte e oito deste beneméritos são declaradamente residentes em Coimbra, e outros vinte podem ser considerados no mesmo grupo tanto por se tratarem homens ligados a instituições da cidade - como Francisco Lopes Teixeira, antigo cónego magistral da Sé de Coimbra e Provedor da Santa Casa da mesma cidade ${ }^{18}$, Miguel dos Rios, prior de São João de Almedina ${ }^{19}$, ou José Maria dos Santos,

17 Vide, a título de exemplo, os casos de Manuel Soares de Oliveira (Arquivo da Misericórdia de Coimbra (AMC), Testamento e ultima disposiçam com que faleceo o lecencedo Manoel Soares de Oliveira, natural que foi da villa de Pereira accessor \& auditor gèral do Governador, \& Capitão General das Ilhas Phelipinas na Cidade de Manilha, aonde faleceo aos 3 de Setembro de 1675. Coimbra: Na Officina de Ioseph Ferreyra, 1680, p. 4); Sebastião de Mendanha Castelo Branco (AMC, Coimbra - 1673, 18 de Abril: Contratto de Sebastiam de Mendanha Castelo Branco provedor que foi desta Santa Caza com João de Seixas Castelo Bramco por que deixa a Misericórdia mil cruzados por sua morte do dito Sebastiaõ de Mendanha para renderem in perpetuum in Documentos Antigos. Tomo 25, fl. 145) e de Francisco Pereira (AMC, s./1. - 1832, 10 de Julho: Registo do testamento serrado com que fallesceu Francisco Pereira negociante morador na rua da Calçada freguesia de São Bartholomeu desta cidade in Testamentos: Vinte e um testamentos e documentos de varios bemfeitores e correspondencia sobre os legados deixados no Brazil (1833-1891). Vol. 27, fl. 8v.).

${ }^{18}$ AMC, Coimbra - 1669, 25 de Novembro: Testamento proprio de nosso irmão e reverendo Doutor Francisco Loppes Teyxeyra, Conego que foi da Sé Cathedral desta cidade, Provisor deste Bispado, e Provedor desta Santa Caza da Mizericordia in Testamentos 19: Testamento do Reverendo Doutor Francisco Lopes Teixeira. 1669.

${ }^{19}$ AMC, Catalogo dos Bemfeitores da S $S^{\text {ta }}$ Casa da Misericordia de Coimbra, suas disposições e Legados, feito por mandato do Ex. ${ }^{\text {mo }}$ D. ${ }^{\text {or }}$ Joaquim Cardozo d'Araujo, Lente Cathedratico da Faculdade de Theologia na Universidade, sendo Provedor no anno de 1866 e 1867. Fl. 79. 
arcediago da Sé de Coimbra ${ }^{20}$ - como por os respectivos testamentos terem sido redigidos em Coimbra, como é o caso das irmãs Maria do Sacramento e Isabel Maria ${ }^{21}$. Dos restantes benfeitores, embora de partes várias, muitos parecem localizar-se em torno da cidade de Coimbra, em locais como Ceira, Condeixa e Lorvão. Mais distantes são os lugares de Estremoz, Matosinhos, Ponta Delgada e até, fora da metrópole, o Brasil e Filipinas.

Relativamente ao género sexual, destacam-se os benfeitores masculinos mas também a disparidade existente entre estes e as mulheres, repartindo-se o universo dos beneméritos entre noventa e dois homens e trinta e uma mulheres.

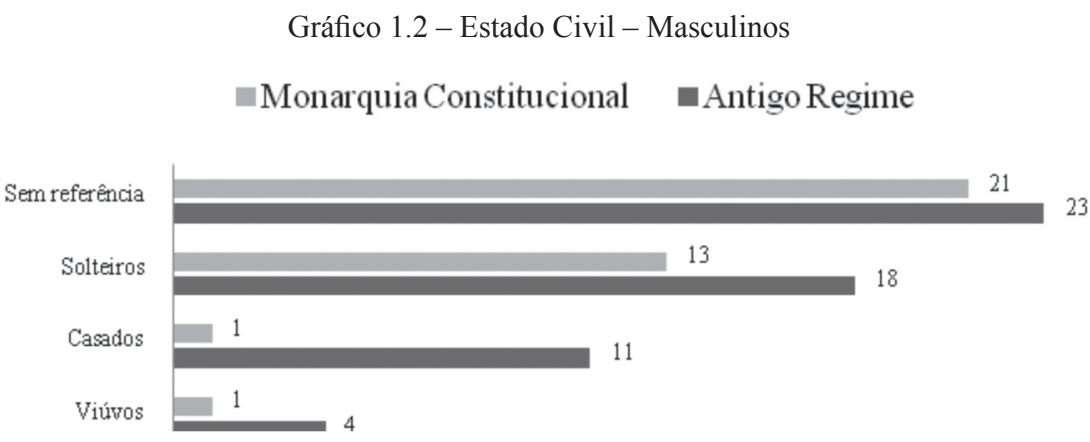

No grupo dos homens sobressaem os solteiros, cujo declive entre épocas não é demasiado acentuado. Casados e viúvos, em menor número, actuaram essencialmente durante o Antigo Regime. Já as mulheres realizaram a maioria das suas doações até 1834, período em que se destacam as casadas, que de resto não actuam durante a Monarquia Constitucional. Em igual número foram as solteiras e as viúvas, que pouco intervieram durante o período do Liberalismo.

${ }^{20}$ AMC, Catalogo dos Bemfeitores..., cit., fl. 171.

${ }^{21} \mathrm{O}$ que significa, pelo menos, um local de residência próximo da cidade de Coimbra AMC, Coimbra - 1736, 20 de Maio: Testamento de Maria do Sacramento e sua irma Izabel Maria solteiras in Documentos Antigos. Tomo 12, fl. 1. 
Gráfico 1.2 - Estado Civil - Masculinos

Monarquia Constitucional $\quad$ Antigo Regime

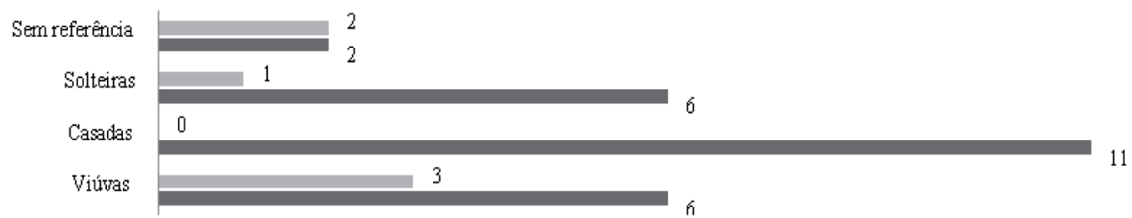

O perfil sócio-profissional dos benfeitores, por sua vez, é bastante diverso e, naturalmente, alterou-se conforme a época. O gráfico abaixo disposto, que contém dados relativos ao número de homens letrados - isto é, indivíduos formados na Universidade: bacharéis, licenciados, doutores; e até lentes dela -, aos fruidores de distinções sociais - Par do Reino ${ }^{22}$, Fidalgo da Casa Real $^{23}$ e três mulheres cujo nome é precedido pelo honroso Dona ${ }^{24}$ e às profissões dos benfeitores, demonstra as diferenças da distribuição dos homens (predominantemente, mas também das mulheres) identificados com determinadas tipologias sociais e profissionais pelas duas épocas.

Gráfico 2 - Atributos sócio-profissionais

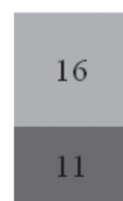
Monarquia Constitucional Antigo Regime

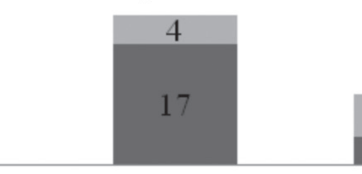

Letrados

Eclesiásticos

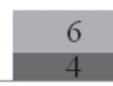

Homens de negócios

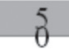

Distinções nobiliárquicas

Salta logo à vista a predominância dos letrados e dos eclesiásticos: os primeiros em número ligeiramente maior durante a Monarquia Constitucional e, inversamente, o estado eclesiástico a actuar em larga escala durante o Antigo Regime, vindo a perder preponderância após a Convenção

${ }^{22}$ António Henriques Seco-AMC, Catalogo dos Bemfeitores... cit., fl. 159.

${ }^{23}$ Amaro Coutinho Pereira e António Pereira de Neiva - respectivamente AMC, Catalogo dos Bemfeitores ... cit., fl., e AMC, Coimbra - 1871, 2 de Agosto: [Traslado do] Testamento [de António da Cunha Pereira Bandeira Neiva] in Testamentos ..., cit.. Vol. 27, fl. 11v.

${ }^{24}$ Guilhermina de Oliveira Lucas, Maria Luísa de Freire e Antónia de Almeida - AMC, Catalogo dos Bemfeitores... cit., fls. 154, 155 e 161, respectivamente. 
de Évoramonte. Na categoria homens de negócios, que agrupa homens com ligação à actividade mercantil, apresentados como «negociante» ou «mercador» sem mais especificação, e duas viúvas destes, verifica-se uma ligeira subida numérica de uma era para a outra, o que também é válido para os homens de Estado ${ }^{25}$. Exclusiva acabou por ser a ocorrência de doações por parte de titulares de distinções nobiliárquicas durante o Liberalismo.

Vemos ainda, em pequeno número, a realizarem doações um conjunto de profissionais 'típicos' de ambas as épocas, que não constam daquele gráfico por serem incomparáveis e que, portanto, são apresentados somente aqui para evitar anacronismos. Durante a Época Moderna realizaram doações um escrivão do eclesiástico, um barbeiro e dois mecânicos ${ }^{26}$, vindo depois o Liberalismo a assistir à emergência das comummente designadas «profissões

${ }^{25}$ Denominação algo perigosa se nos ativermos à parcimónia existente no meio académico quanto ao emprego da designação Estado antes do Liberalismo. Não obstante estarmos conscientes do risco em que incorremos ao empregá-la, julgámos ser a mais apropriada para definir um conjunto de homens que se encontravam ao serviço da Coroa, na administração central e colonial e no ramo militar - em suma, do poder central. Os titulares e os cargos em causa são: o assessor e auditor do governador e capitão-geral das Filipinas, Manuel Soares de Oliveira (1675); o conselheiro de Sua Majestade e deputado da Mesa da Consciência e das Ordens, Francisco de Carvalho e Albuquerque (1822); o desembargador do Paço, Francisco de Fonseca Montanha (1825); o conselheiro de Sua Majestade e desembargador José Pires da Costa (1871); o tesoureiro do Império do Brasil e província do Rio de Janeiro; Joaquim Nunes de Carvalho (1872); o sub-director da Secretaria de Estado da Marinha e do Ultramar Simão Soriano (1891); o conselheiro António Henriques Seco (1892); coronel Manuel Freire de Andrade (1864) e o tenente-general Bernardo José de Abreu (1878) - cf. AMC, Testamento e ultima disposiçam ..., cit.; AMC, Lisboa - 1822, 22 de Novembro: [Traslado do] Testamento [de Francisco Pires de Carvalho e Albuquerque] in Testamentos 26: Quatorze testamentos de varios bemfeitores e documentos respetivos (1784-1833); Coimbra - 1825, 10 de Março: Publica forma do testamento com que falesceo o Desembargador do Paço Francisco António Duarte da Fonseca Montanha Oliveira e Silva in Testamentos 26..., cit.; Coimbra - 1871, 24 de Fevereiro: Registo do testamento cerrado com que falleceo o Dezembargador José Filipe Pires da Costa na freguezia de São Bartholomeu desta cidade in Testamentos..., cit. Vol. 27; AMC, Catalogo dos Bemfeitores ... cit., fls. 140, 145, 149, 156, 157 e 159.

${ }^{26}$ Manuel de Abreu (1680), o latoeiro João Francisco (1684), ourives António de Abreu (1742) e Manuel de Brito da Silva (1747) - cf. AMC, Catalogo dos Bemfeitores..., cit., fls. 72 e 76, 106 e 109; e s./l. - s./d.: Instromento de testamento com que falesceo Manuel de Brito barbeiro desta cidade in Documentos Antigos. Tomo 9. 
liberais»: quatro profissionais da saúde ${ }^{27}$, um engenheiro civil, um advogado e um professor de Filosofia do ensino liceal ${ }^{28}$.

Verifica-se também a existência de uma relação entre certos benfeitores e a Santa Casa que financiavam, sendo para este efeito considerados quer os treze irmãos - alguns dos quais haviam sido provedor, tesoureiro ou escrivão $^{29}$-, quer as viúvas ou a filha de irmãos ${ }^{30}$, ou ainda aqueles três benfeitores que foram órfãos dos colégios da Santa Casa ${ }^{31}$.

As características individuais da totalidade dos benfeitores são, no seu conjunto, bastante diversas. À luz dos dados fornecidos pela documentação consultada evidencia-se a hegemonia de homens solteiros e dos residentes em Coimbra ou nas suas proximidades. No Antigo Regime possuem uma maior expressividade os eclesiásticos enquanto no Liberalismo não se verifica a hegemonia de nenhum grupo. Negociantes, homens de Estado e detentores de títulos académicos marcam presença ao longo de todo o período estudado, sem grande concentração numa ou noutra época, embora se destaquem com pouca ênfase durante a Monarquia Constitucional. Outra novidade no conjunto dos filantropos, no sentido estrito que acima se falou, dos benfeitores do Liberalismo, portanto, é o aparecimento das «profissões liberais» e dos distinguidos com títulos honoríficos.

${ }^{27}$ Os farmacêuticos José Santos Mesquita (1862) e Manuel António da Silva (1894) e os médicos José Miranda Pio (1858) e Manuel Lopes Guimarães (1903) - cf. AMC, Catalogo dos Bemfeitores... cit., fls. 138, 158, 136-136v. e 167.

${ }^{28}$ Respectivamente, Manuel de Lima Figueiredo (1890), Constantino Alves da Silva (1909), e José Adelino Serrasqueira (1909) - cf. AMC, Catalogo dos Bemfeitores... cit., fls. 160 e 169 .

${ }^{29}$ João Francisco (1684), João Mendes de Carvalho (1698), André Bernardes Aires (1705), Martinho Pires Caldeira (1711), Manuel de Rocha Almeida (1730), Manuel Brito Silva (1747), Filipe de Macedo Guimarães (1754) e António Pinto Machado (1779) cf. AMC, Catalogo dos Bemfeitores... cit., fls. 76, 84, 88, 89, 100, 109, 114 e 116. Ocuparam os referidos cargos Francisco Lopes Teixeira, Sebastião Castelo Branco, Francisco de Arantes (1869), Manuel da Silva Rocha (1882) e Manuel Marques Figueiredo (1889) - cf. AMC, Coimbra - 1669, 25 de Novembro: Testamento proprio de nosso irmão e reverendo Doutor Francisco Loppes Teyxeyra..., cit.; Coimbra - 1673, 18 de Abril: Contratto de Sebastiam de Mendanha Castelo Branco..., cit; e Catalogo dos Bemfeitores... cit., fls. 144, 151 e 153.

${ }^{30}$ Maria da Costa (1680), Maria Rodrigues (1693); Sebastiana Maria (1746) e Sebastiana da Luz (1744) - cf. AMC, Contrato de missa cotidiana que fes a Santa Misericórdia com Maria da Costa..., cit., fl. 31; Coimbra - 1693, 4 de Julho: Treslado do testamento de Maria Rodrigues..., cit., fl. 424; e Catalogo dos Bemfeitores... cit., fls. 108 e 107.

${ }^{31}$ Tomé de Almeida Cabral (1855), Maria das Dores Simões (1876) e Manuel António da Silva (1894) - AMC, Catalogo dos Bemfeitores ... cit., fls. 135, 148, 158. 
No que toca às obras assistenciais, do espírito e do corpo, observamos que das cento e dez doações realizadas entre 1668 e 1910, somente treze benfeitores não definiram qualquer legado para ser cumprido. A soma de todas elas, todavia, não coincide com os totais referentes a números de legados e de benfeitores, nem mesmo se consideradas as subtracções apontadas, pois uma doação não corresponde, obrigatoriamente, a apenas um legado.

$\mathrm{O}$ quadro abaixo exposto ${ }^{32}$ arrola os legados mais frequentemente encomendados à Santa Casa da Misericórdia de Coimbra, sendo deixados de parte os poucos casos que constituem determinada originalidade e que, por isso, não foram considerados. Estabelece ainda a relação de cada um deles com as diversas tipologias sociais que constituem o universo dos benfeitores conforme os períodos em que actuaram.

A instituição de capelas, como atrás se declarou, foi durante o século XVII um meio de enriquecimento de maior importância das misericórdias portuguesas. No caso de Coimbra, a encomendação deste legado pio não se limitou a essa centúria e continuou a revelar bastante vigor pelo século XVIII fora. Daqui até ao fim do período em estudo poucos terão sido os casos.

Esta quebra foi claramente provocada pelo magistério do marquês de Pombal. A 9 de Setembro de 1769, foi determinado que apenas a terça parte das terças das heranças podia ser encaminhada para a satisfação de legados pios, não podendo exceder os quatrocentos mil réis excepto se fossem encomendados às misericórdias que, entre outras instituições, estavam admitidas a receber até oitocentos mil réis. As capelas, mais especificamente,

${ }^{32}$ Legenda: Estado civil - S (solteiro), C (casado), V (viúvo), SR (sem referência); Atributos sócio-profissionais - L (letrado e/ou lente), DS (distinção social), E (eclesiástico), $\mathrm{HN}$ (homem de negócios), HE (homem de Estado), O (outros), SR (sem referência). Na grelha feminina, as abreviaturas utilizadas nas colunas do estado civil correspondem às utilizadas na masculina e, no segundo campo, o dos atributos sócio- profissionais, DS significa a distinção social e M/V/FHN significa mulher, viúva ou filha de homem de negócios. A coluna Misericórdia significa, no campo masculino, que o benfeitor estava de algum modo ligado à Santa Casa, quer por ter sido irmão ou exercido algum cargo na administração da mesma quer tivesse sido acolhido no colégio de órfãos São Caetano. No caso feminino, corresponde tão-só a mulher, filha ou viúva de irmão ou órfã de São Caetano. 
Quadro 1 - Relação entre benfeitores e legados

\begin{tabular}{|c|c|c|c|c|c|c|c|c|c|c|c|c|c|c|c|c|c|c|c|c|}
\hline & \multicolumn{12}{|c|}{ Masculinos } & \multicolumn{7}{|c|}{ Femininos } \\
\hline & & \multicolumn{4}{|c|}{ Estado civil } & \multicolumn{7}{|c|}{$\begin{array}{c}\text { Atributos } \\
\text { sócio-profissionais }\end{array}$} & \multirow{2}{*}{ 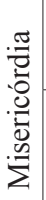 } & \multicolumn{4}{|c|}{ Estado civil } & \multicolumn{2}{|c|}{$\begin{array}{l}\text { Atributos } \\
\text { sociais }\end{array}$} & \multirow{2}{*}{ 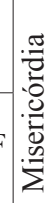 } \\
\hline & & S & $\mathrm{C}$ & V & SR & $\mathrm{L}$ & DS & E & $\mathrm{HN}$ & $\mathrm{HE}$ & $\mathrm{O}$ & SR & & $\mathrm{S}$ & $\mathrm{C}$ & $\mathrm{V}$ & SR & DS & $\begin{array}{c}\mathrm{M} / \mathrm{V} / \mathrm{F} \\
\mathrm{HN}\end{array}$ & \\
\hline \multirow{7}{*}{ 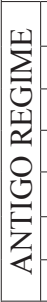 } & Capelas & 11 & 11 & 1 & 13 & 6 & & 10 & 1 & 1 & 2 & 18 & 9 & 4 & 11 & 4 & 3 & & 2 & 5 \\
\hline & Esmolas & 2 & 1 & 2 & 6 & 4 & & 2 & & 2 & & 5 & 4 & & 2 & 1 & & & & 2 \\
\hline & Tenças & 7 & & 1 & 1 & 4 & & 6 & & & 1 & & 3 & & 1 & 1 & & & & \\
\hline & Dotes & 4 & & 2 & 2 & 3 & & 4 & 1 & 1 & 1 & 1 & 2 & & & & & & & \\
\hline & Expostos & 2 & & 1 & 5 & 3 & & 1 & 2 & & & 2 & & 1 & & & & & & \\
\hline & Órfãos & 2 & & 1 & 2 & 4 & & 2 & & 3 & & & & 1 & & 1 & & & & 1 \\
\hline & S.R. & 1 & & & 1 & 1 & & 1 & & & & & & & & & & & & \\
\hline \multirow{7}{*}{ 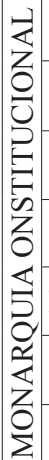 } & Capelas & 1 & & & 3 & 2 & & & & & & 2 & & & & 1 & 1 & 1 & & \\
\hline & Esmolas & 3 & & & 2 & 3 & & 21 & & & & 2 & 1 & & & & 2 & 1 & & \\
\hline & Tenças & 4 & & & 4 & 2 & & & 1 & 2 & 1 & 4 & 2 & & & & & & & \\
\hline & Dotes & & & & & & & & & & & & & 1 & & & & & & \\
\hline & Expostos & 2 & & & & 1 & 1 & & 1 & & & & & & & & & & & \\
\hline & Órfãos & 3 & & & 5 & 3 & & & & 2 & 3 & 2 & 3 & & & 1 & & & & 1 \\
\hline & S.R. & 3 & 1 & & 6 & 4 & 2 & 1 & 1 & 2 & 2 & 1 & & & & 1 & & 1 & & \\
\hline
\end{tabular}

não podiam ser financiadas com base em bens imóveis, mas apenas com dinheiro ${ }^{33}$.

O efeito das limitações impostas é por de mais evidente na Misericórdia de Coimbra: das quarenta e oito capelas instituídas, quarenta e duas foram encomendadas antes do ano da lei e as restantes seis depois de 1779. A restrições legais que atingiram as capelas também afectaram as doações em geral, como revela a ausência de instituição de legados entre 1786 e

${ }^{33}$ Esta lei, em parte, acabou por ser suspensa em 1778, sendo depois retomada em 1796 cf. LOPES, Maria Antónia e PAIVA, José Pedro - Portugaliae Monumenta Misericordiarum. Vol. 7: Sob o signo da Mudança: de D. José I a 1834. Lisboa: União das Misericórdias Portuguesas, ANO, p. 3. 
1809, cuja regularidade foi retomada somente a partir do segundo decénio de Oitocentos.

Os efeitos causados pela legislação pombalina sobre a instituição de capelas, às quais os benfeitores tinham particular devoção e que até então constituíam uma forte motivação à doação de bens à Misericórdia de Coimbra, terão contribuído fortemente para suspensão e subsequente perda de ímpeto do ritmo das doações. Para tamanha quebra poderão também ter contribuído os graves problemas financeiros e administrativos, mercê de «desleixo ou fraudes» com que as misericórdias se depararam na altura ${ }^{34}$. Esta situação poderá ter diminuído o prestígio da instituição e, por conseguinte, provocado a suspensão das doações.

No que toca à relação entre a capela encomendada e o benfeitor seu instituidor, existe uma relativa transversalidade aos vários perfis, tendo sido encomendada abundantemente por homens e por mulheres. No caso dos primeiros, solteiros e casados assumem uma importância semelhante. Excluindo-se os benfeitores sem qualquer referência, a primazia da encomendação de capelas pertence aos eclesiásticos, o que será justificado, para além da sua elevada expressão numérica no cômputo geral de beneméritos, pela sua expectável sensibilidade religiosa. A única categoria capaz de se destacar entre a altíssima taxa de encomendação de capelas por eclesiásticos e as restantes que se definem por uma baixa expressividade é mesmo a dos letrados, muitos dos quais homens da Igreja.

Quanto às mulheres, viúvas e solteiras aparecem em igual número, sendo ambas superadas pelas casadas, que se destacam. A justificação deste fenómeno reside no facto de muitas destas realizarem as suas doações e encomendação de capelas em parceria com os respectivos esposos, fenómeno que não ocorreu depois de 1834. Mais nos parece ser importante destacar a actuação de homens e mulheres ligadas à Misericórdia, no caso dos homens, irmãos e seus antigos dirigentes, e no das mulheres, esposas ou viúvas de irmãos. Tais observações, porém, reportam-se somente às encomendações levadas a cabo durante o Antigo Regime, visto terem rareado no período liberal. Nesta época, homens e mulheres instituíram capelas em

${ }^{34}$ LOPES, Maria Antónia e PAIVA, José Pedro - Portugaliae Monumenta Misericordiarum. Vol. 7 ..., cit., p. 5. 
número diminuto e não se verifica nenhuma clivagem acentuada entre os dois géneros.

Embora dominante, a criação de capelas variou quanto às suas diversas determinações, sendo o principal factor de originalidade de capela para capela o número de missas correspondentes, que tanto podiam ser de periodicidade anual - desde apenas duas ${ }^{35}$ até cento e oitenta e três ${ }^{36}-$,

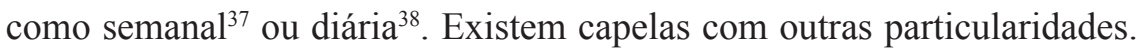
Maria Rodrigues, por exemplo, estipulou diferentes horários para a realização das missas no Verão e no Inverno ${ }^{39}$. Manuel Soares de Oliveira fundou seis capelas em 1698, devendo cada uma corresponder a um dia específico da semana e ser a respectiva missa celebrada por um capelão próprio ${ }^{40}$. As referidas particularidades reportam-se todas ao primeiro período, à segunda metade do século XVII, época por excelência da encomendação de capelas. Tais determinações, assaz rigorosas, prender-se-ão porventura à religiosidade dos benfeitores que, como acima se expôs, correspondia às sensibilidades típicas da época, e não tanto a outro factor, visto não existir nenhum padrão que enforme os autores destas rigorosas exigências numa determinada tipologia.

A outorga de dinheiro para ser distribuído sob a forma de esmolas assume também um papel revelante. Referimo-nos às dezanove doações destinadas a financiar a atribuição de esmolas aos desvalidos de Coimbra e distribuídas com igual peso pelo Antigo Regime e pelo Liberalismo». Os potenciais beneficiados, porém, não o seriam indiscriminadamente. As esmolas tanto

${ }^{35}$ O prior António Pestana (1672) - AMC, Catalogo dos Bemfeitores..., cit., fl. 64.

${ }^{36}$ Nicolau Gomes de Oliveira (1672) - AMC, Catalogo dos Bemfeitores..., cit., fl. 65.

${ }^{37}$ Ana Pinheira (1694) - AMC, Catalogo dos Bemfeitores ..., cit., fl. 80.

${ }^{38}$ Vide em AMC, Catalogo dos Bemfeitores..., cit., fls. 67, 75 e 77, os casos de Pedro Simões (1674), dos irmãos António dos Reis e Joana Baptista dos Reis (1683) e dos também irmãos Antónia Ferreira e Gaspar Ferreira (1683), respectivamente.

${ }^{39}$ AMC, Coimbra - 1673, 7 de Fevereiro: Escritura de hũa missa comtidiana que foi [riscado] Maria Rodrigues Minhota viuva in Documentos Antigos. Tomo 16, fl. 172.

${ }^{40}$ AMC, Testamento e ultima disposiçam..., cit., fls. 4-5. 
podiam visar de um modo genérico os pobres ${ }^{41}$, como mais especificamente os doentes ${ }^{42}$ e os presos da cadeia ${ }^{43}$.

Contrariamente ao verificado na instituição de capelas, não se nota nenhuma tendência. Salienta-se apenas uma maior preferência pela parte dos benfeitores masculinos, o que pode ser justificado pela sua desproporcional superioridade numérica em relação às mulheres no universo geral dos benfeitores. No grupo masculino, solteiros, casados e viúvos encomendaram-nas, sem grandes diferenças entre si, tanto no Antigo Regime como na Monarquia Constitucional. Neste segundo tempo, todavia, destacam-se os eclesiásticos, cuja proeminência dever-se-á, porventura, ao declínio da instituição de capelas, tendo provavelmente estes homens procurado praticar outra obra tradicionalmente valorizada pela liturgia cristã e tão praticada ao longo dos tempos. Neste caso, encontramos ainda uma relativamente forte actuação de homens ligados à Santa Casa, quatro antes de 1834 e somente um depois dessa data.

Acima afirmámos que a par do intento da protecção social caminhava, também, uma intenção de controlar socialmente. Ao promover esta e outras obras o benfeitor, para além de definir (ou não) a identidade dos desvalidos que pretendia assistir, podia restringir ainda mais o grupo de candidatos ao considerar a conduta moral dos candidatos. Bem ilustra a nossa afirmação a doação de Francisco de Carvalho e Albuquerque destinada a criar um fundo de um milhão de réis para ser distribuído por órfãos e viúvas de «honesto procedimento» ${ }^{44}$.

A prévia definição do perfil dos possíveis beneficiados pelo legado deixado também se encontra patente na atribuição de tenças, que se distribuem quase igualitariamente pelo Antigo Regime e pela Monarquia Constitucional. Por tenças entendemos a criação de um fundo destinado à entrega regular de uma soma a algum indivíduo previamente apresentado ou sujeito a concurso, a um colectivo de pessoas ou ainda a uma instituição ${ }^{45}$.

\footnotetext{
${ }^{41}$ AMC, Catalogo dos Bemfeitores..., cit., fl. 93.

${ }^{42}$ Manuel Mendes Lopes determina a aplicação dos juros gerados com o seu capital aos "pobres doentes e entrevados" - AMC, Catalogo dos Bemfeitores..., cit., fl. 115.

${ }^{43}$ AMC, Catalogo dos Bemfeitores..., cit., fl. 88.

${ }^{44}$ AMC, Catalogo dos Bemfeitores..., cit., fl. 120.

${ }^{45}$ Referimo-nos aos casos de José Leitão Teles, que encomenda a entrega anual de dez mil reis aos padres de Santo António, e de João Francisco, cujo legado originaria uma
} 
Algumas destas dezassete tenças, no entanto, destinavam-se a indivíduos próximos ao benfeitor, como é o caso do legado de Manuel Tavares que determina a colocação a juros de cento e cinquenta mil réis, para o respectivo rendimento ser anualmente entregue às suas duas irmãs ${ }^{46}$.

Particulares acabam por ser os legados de Bento Soares da Fonseca, Tomé Cabral, José Miranda Pio e Simão Soriano, que instituem autênticas bolsas de estudo. São precisamente algumas destas tenças que, de certo modo, vão ao encontro da referida prática de controlo social. Bento Soares da Fonseca, em 1730, apesar de não definir nenhuma conduta moral obrigatória, restringe bastante as possibilidades de candidatura ao benefício: a pensão destinava-se a um parente seu dos mais chegados e de sangue puro ${ }^{47}$. Não sendo propriamente de uma prática reguladora dos hábitos sociais, acabava todavia por excluir determinados elementos, indesejáveis à luz do modelo segregacionista vigente antes da extinção da diferenciação entre cristão-novo e cristão-velho. João Miranda Pio, por outro lado, dava preferência apenas aos estudantes que tendo iniciado o curso de Medicina não tivessem possibilidades financeiras de prosseguir os estudos. Em todo o caso, estes estavam obrigados a apresentar no final de cada ano lectivo um atestado passado pelos seus professores que comprovasse o seu aproveitamento escolar ${ }^{48}$. Mais exigente no que respeita aos comportamentos dos estudantes, Simão Soriano definia que a tença devia ser entregue a «trez estudantes pobres, e de boa conduta moral e civil reunida com a sua aplicação e talentos» ${ }^{49}$.

Neste tipo de legados, demarcam-se das restantes tipologias os homens solteiros. Nem um casado e apenas um viúvo (excepto os sem qualquer

doação anual aos mesmos clérigos, mas para que estes comprassem quatro velas de arrátel por ocasião do dia do seu santo padroeiro - cf. AMC, Catalogo dos Bemfeitores..., cit., fls. 90 e 76 .

${ }^{46}$ AMC, Catalogo dos Bemfeitores..., cit., fl. 71.

${ }^{47} \mathrm{AMC}, \mathrm{s} / \mathrm{l}$ - s/d: Copia das declaraçõens, que mandou o reverendo padre Bento Soares da Fonseca assistente na cidade da Bahia in Contrato do reverendo padre Bento Soares. fl. $11 \mathrm{v}$.

${ }^{48}$ AMC, s/1 - 1858, 20 de Novembro: Certidão in Testamentos ..., cit.. Vol. 27, s/n.

49 AMC, s/1 - 1891, 11 de Março: [Traslado] testamento cerrado [de Simão José da Luz Soriano], que se acha registado na Administração do terceiro bairro d'esta cidade a folhas vinte e nove verso do Livro numero vinte e um da freguezia das Mercês, no qual, entre outras disposições, ha o seguinte in Testamentos ..., cit. . Vol. 27, fl. 4v.. 
referência, claro). No Antigo Regime, eclesiásticos e letrados, enquanto do segundo terço de Oitocentos para a frente, embora em pequeno número, homens de negócios, homens de Estados e outras profissões, parecem substituí-los. As mulheres surgem em escasso número, sendo uma casada e outra viúva, e exclusivamente durante o Absolutismo. Tenças que, como acabou de ser observado, assumiram diversas formas de atribuição, mas que nos parecem ser típicas de homens que, tendo vivido solteiros, ou não tinham ninguém a quem deixar os seus bens, canalizando-os portanto para instituições de sua devoção - os religiosos de Santo António - ou para projectos que valorizavam - auxílio financeiro de estudantes pobres, o que provavelmente justificará a proeminência dos letrados -, ou que, enquanto vivos, tinham tido alguém que lhes era dependente e cuja futura subsistência procuravam assegurar.

A concessão de dotes assumiu durante o período aqui em estudo uma certa relevância. A sua importância prendia-se às «dificuldades nupciais da gente pobre», uma vez que o casamento era «um factor de empobrecimento para os homens». Contrair matrimónio, em especial com mulheres pobres, representava um risco, pelo que importava tornar o casamento atractivo. O alvo do gesto, contudo, eram as mulheres e não os homens e focava outros interesses que não apenas o da assistência: «Ao fazer-se mercê de um dote a uma rapariga pobre, honrada e órfã [...], o que se pretendia acima de tudo era a sua preservação moral, não a solução de uma situação económica ou de sofrimento» ${ }^{50}$. Não apenas assistência ao desvalimento mas também controlo social, portanto.

Comprovam esta assunção as várias disposições estabelecidas pelos beneméritos instituidores de dotes. José de Morais, por exemplo, determinou que se desse todos os anos um dote no valor de um conto de réis a uma órfã de S. Martinho de Árvore ou de São Delgas, posto que ela fosse seleccionada pelo Provedor da Misericórdia e ainda «a mais bem procedida, e livre e izenta de toda $[\ldots]$ suspecta e prestituição» ${ }^{51}$. Semelhante é a exigência de Francisco Pereira, que ordena a distribuição de dois dotes anuais por «pessoas

\footnotetext{
${ }^{50}$ LOPES, Maria Antónia - Protecção Social..., cit., p. 89-90.

${ }^{51}$ AMC, São Martinho da Árvore - 1829, 18 de Janeiro: Registo do testamento serrado com que faleceo o reverendo Joze de Moraes vigario da igreja e freguezia de São Martinho d'Árvore in Testamentos 26..., cit., fls. 4 e 4v.
} 
solteiras de boa reputacam $\rangle^{52}$. Manuel de Abreu, por seu turno, deixava um dote à própria filha para que esta ingressasse na vida monástica ou casasse. Impunha porém que, se ela falecesse ou casasse sem a aprovação da Santa Casa, o dinheiro revertesse a favor dos cofres da confraria ${ }^{53}$.

Teve esta obra assistencial uma expressão acentuadamente moderna; mas também masculina, sendo a única instituição de dotes pós-Évoramonte realizada por uma mulher: homens solteiros, sem uma acentuada disparidade em relação ao viúvos, mas que se distribuem por várias das categorias socioprofissionais, embora os eclesiásticos e letrados detenham um maior peso e, portanto, pareçam representar os instituidores mais habituais deste legado. Neste caso, tal como no anterior, ainda pontificam os homens ligados à Misericórdia, pelo menos durante o período absolutista.

As crianças, nomeadamente os expostos e os órfãos, constituem o último dos grupos que os benfeitores da Santa Casa mais procuraram auxiliar, embora quase exclusivamente apenas durante o século XIX. Apesar de a Misericórdia de Coimbra deter desde 1706 o encargo de criar os enjeitados ${ }^{54}$, a canalização de heranças para esse efeito regista-se somente a partir de 1821. A aplicação destes fundos pela Santa Casa, porém, não perdurou, já que em 1836 Passos Manuel decretou a passagem da responsabilidade das rodas para as Câmaras ${ }^{55}$.

Tendência de Oitocentos, como foi dito, e claramente masculina. A excessiva falta de referências sobre o estado civil dos benfeitores não permite estabelecer um padrão concreto nesta área. Ao invés, verifica-se a predominância de letrados na generalidade, a presença de homens de negócios antes de 1834 e de homens de Estado e dos ligados a outras

${ }^{52}$ AMC, s/1 - 1833, 10 de Julho: Registo do Testamento serrado com que fallesceu Francisco Pereira..., cit.. Vol. 27, fl. 9.

${ }^{53}$ AMC, Catalogo dos Bemfeitores..., cit., fl. 106.

${ }^{54}$ LOPES, Maria Antónia - Pobreza, Assistência e Controlo Social em Coimbra (1750-1850). Vol. II. Viseu: Palimage Editores, 2000, p. 177.

${ }^{55}$ Cf. Doc. 17 in LOPES, Maria Antónia e PAIVA, José Pedro - Portugaliae Monumenta Misericordiarum. Vol 8..., cit., p. 54. Em Coimbra, a transferência das responsabilidades não se operou nem fácil nem rapidamente, tendo a Câmara assumido o seu dever somente em 1839 e após um longo litígio - cf. LOPES, Maria Antónia - Pobreza, Assistência ..., cit., p. 200-202. 
actividades profissionais depois desse ano. De destacar é a ausência de gente ligada à Misericórdia, contrária ao verificado nas obras atrás analisadas.

Os benfeitores que procuraram assistir os órfãos, por outro lado, encontravam-se ligados à Santa Casa, embora a sua relação fosse, grosso modo, de natureza diferente das anteriormente referidas. Dois dos três homens ligados à Misericórdia que canalizaram os seus bens para os órfãos durante o Liberalismo eram antigos órfãos e, das duas mulheres que também o fizeram, o único caso ocorrido depois de 1834 também se tratava de uma antiga colegial.

No seu conjunto, as doações orientadas para esta obra ocorreram quase apenas durante Oitocentos, embora anteriormente, no final do século XVII, os órfãos já tivessem sido visados por Manuel Soares de Oliveira, que encomendara a fundação de dois colégios de órfãos na cidade de Coimbra ${ }^{56}$. Na realidade, somente um deles, o feminino, seria criado. O colégio destinado a meninos órfãos surgiria apenas a 15 de Janeiro de $1804^{57}$, tendo na sua origem a herança de Caetano Correia Seixas ${ }^{58}$. Segundo indica o quadro já referido, foram os homens quem mais buscaram esta obra, essencialmente letrados no Antigo Regime, homens de Estado em ambas as épocas, e outros durante a Monarquia Constitucional. Tal como o ocorrido no caso dos expostos, as mulheres parecem ter concedido pouca atenção aos órfãos.

Parece-nos, pois, indispensável falar da popularização dos legados tomando em consideração as circunstâncias e épocas que assistiram à encomendação de cada uma das obras, bem como os autores das doações, não fossem as formas de assistência «simultaneamente reflexo de uma realidade, espelho de um sentir comum e instrumento ideológico que infunde novas formas de sensibilidade e novas atitudes mentais» ${ }^{59}$.

Embora dominante em termos numéricos, a instituição de capelas foi evidentemente um fenómeno do Antigo Regime, com pouca expressão a

${ }^{56}$ AMC, Testamento e ultima disposiçam..., cit., fls. 8 e ss.

${ }^{57}$ LOPES, Maria Antónia - Pobreza, Assistência..., cit., p. 334-335.

${ }^{58}$ AMC, Coimbra - 1786, 15 de Novembro: Testamento com que falesceo o Reverendo Conego Caetano Correa Seixas lente jubilado nesta Universidade de Coimbra in Testamento do Reverendo Doutor Caetano Correia Seixas e comprimento de legados. fl. 4.

${ }^{59}$ LOPES, Maria Antónia - Os pobres e a assistência pública in MATTOSO, José (dir.) - História de Portugal. Vol. V: O Liberalismo. Lisboa: Editorial Estampa, 1994, p. 501. 
partir de 1769, cuja encomendação foi transversal aos diversos perfis sociais dos benfeitores mas no qual, apesar de tudo, se destaca o protagonismo dos eclesiásticos. O Antigo Regime foi também palco da proliferação de dotes, maioritariamente encomendados por homens e, tal como no caso anterior, de tutela eclesiástica. Após 1834 não desfrutaram de muita popularidade.

Por seu turno, a Monarquia Constitucional foi um período fértil no que respeita à assistência aos órfãos e expostos. Aqui os homens da Igreja parecem ter perdido o seu anterior protagonismo, como sucedeu na generalidade, sendo patente a intervenção de diversas tipologias socioprofissionais. Comuns a ambas as épocas, as esmolas e as tenças também ocuparam lugar de destaque no conjunto de legados encomendados essencialmente por homens mas também por mulheres à Santa Casa da Misericórdia de Coimbra. Estes dois legados, juntamente com os dotes, permitiam ainda aos benfeitores controlar os hábitos sociais dos beneficiados, excluindo do campo de acção da obra assistencial instituída todo aquele que tivesse qualquer comportamento considerado desviante ou não correspondesse às expectativas de diversa ordem do seu patrono. Alheios a esta intenção parecem ser os legados instituídos em prol das crianças levados a cabo por homens porventura mais afectos ao espírito da filantropia e não tanto a dogmas religiosos. 